\title{
Pemahaman Hadis dan Implikasinya pada Praktek Keagamaan Jamaah Tabligh (Kajian Living Hadis di Kota Bengkulu)
}

(Understanding Hadith and Its Implications on the Religious Practices of the Tablighi Jamaat (Study of Living Hadith in Bengkulu City))

\section{Aan Supian, Ahmad Farhan}

Institut Agama Islam Negeri (IAIN) Bengkulu, Indonesia

aansupian2015@gmail.com, babafaqih@gmail.com

DOI: $10.29240 /$ alquds.v5i2.2501

Submitted: 2021-02-11 | Revised: 2021-08-06 | Accepted: 2021-08-21

\begin{abstract}
This study was conducted to find out how the Tablighi Jamaat's understanding of the Sunnah of the Prophet and to describe the practice of the Prophet's traditions among the Tablighi Jamaat. The type of this research is a field research that used a phenomenological approach with a qualitative descriptive method. Research informants are members of the Tablighi Jamaat who were randomly selected based on their needs. In order to obtain the data in this study, the researcher used direct observation methods, extracting the information through interview and documentation based. The research findings confirmed that the Tablighi Jamaat defined the term of sunnah tends to lead to the definition that narrated by Hadith scholars. The definition of hadith in question is all things that are relied on the Prophet Muhammad either when he has been appointed as a prophet or afterward (Qabla al-Bi'stab ay Ba'dabu), including every word and deed, nature and things. Therefore, there is an understanding that the Tablighi Jamaat becomes necessary to follow everything that came from the Prophet Muhammad. Those all were stated as sunnah, even though the practice of the Prophet Muhammad was in the capacity of an ordinary human being. In general, the Tablighi Jamaat used the works of Maulana Muhammad Zakaria Yusuf al-Kandahlawi and Maaulana Muhammad Yusuf alKandahlawi as references in worships and charity. Moreover, the Muntakhab Ahadis and Fadhail A'mal books are the main consumption in every taklim and recitation activities (read; bayan) of the congregation. However, not all congregations knew and even memorized the hadiths that used as evidence in doing charity.
\end{abstract}

Keywords: Hadith understanding, Tablighi Jamaat, Living Hadith

Abstrak: Penelitian ini dilakukan untuk mengetahui pemahaman Jamaah Tabligh terhadap sunnah Nabi, untuk mendeskripsikan pengamalan hadis-hadis Nabi di kalangan Jamaah Tabligh. Ini merupakan penelitian lapangan (field research) yang menggunakan pendekatan fenomenologi dengan metode deskriptif kualitatif. Informan penelitian 
adalah anggota jamaah tabligh yang dipilih secara acak berdasarkan kebutuhan. Untuk mendapatkan data dalam penelitian ini, maka penulis menggunakan metode pengamatan langsung (observasi), penggalian informasi atau wawancara serta dokumentasi. Temuan penelitian ini menegaskan bahwa Jamaah Tabligh mendefinisikan terma sunnah cenderung mengarah kepada definisi yang dinarasikan oleh ulama Hadis. Hadis yang dimaksud adalah semua hal yang disandarkan kepada Nabi Muhammad saw baik ketika beliau telah diangkat menjadi Rasul atau sesudahnya (Qabla al-Bi'stab ay Ba'dahu), meliputi setiap perkataan dan perbuatan, sifat dan hal ikhwal. Oleh karenanya, ada pemahaman Jamaah tabligh menjadi niscaya untuk mengikuti segala sesuatu yang bersumber dari Nabi Muhammad Saw. Semua itu difahami sebagai sunnah, walaupun dilakukan Nabi Muhammad saw dalam kapasitas manusia biasa. Umumnya jamaan tabligh menjadikan karya Maulana Muhammad Zakaria Yusuf al-Kandahlawi dan Maulana Muhammad Yusuf al-Kandahlawi sebagai referensi dalam beramal. Terlebih kitab Muntakhab Ahadis dan Fadhail A'mal menjadi konsumsi utama dalam setiap kegiatan pengajian (baca; bayan) jamaah. Akan tetapi tidak semua jamaah mengetahui bahkan hafal hadis-hadis yang dijadikan bujjah dalam beramal.

Kata Kunci: Pemahaman hadis, Jamaah Tabligh, Living Hadis

\section{Pendahuluan}

Dalam kedudukannya sebagai sumber ajaran Islam, hadis Nabi saw. memiliki posisi yang sangat penting, Hadis termasuk sumber ajaran Islam yang kedua (al-Mashdar al-Tsani) setelah al-Qur'an. Hadis dikatakan sumber ajaran, karena ia merupakan muara atau rujukan bagi umat Islam ,yang terkait dengan akidah, ibadah, akhlak dan berbagai aspek lainnya selama hidup di dunia untuk bekal kehidupan di akhirat. Hadis merupakan tuntutan, pedoman dan jalan hidup (way of life) serta sumber hukum bagi umat Islam. Keharusan untuk menjadikan hadis sebagai tuntunan dan pegangan dalam kehidupan, antara lain didasarkan pada firman Allah QS. al-Anfal/8: 20 yang artinya: "Hai orang-orangyang beriman, taatlah kepada Allah dan rasul-Nya dan janganlah kamu berpaling daripada-Nya, sedang kamu mendengar (perintah-perintah-Nya)." Ayat lain yang senada terdapat dalam QS. Al-Hasyr/59: 7 yang artinya: "Apa yang dibawa rasul-Nya maka ambillah, dan apa yang dilarangnya maka tinggalkanlah. Dan bertakwalah kepada Allah, sesungguhnya Allah sangat keras bukuman-Nya."

Dalam hubungannya dengan al-Qur'an, hadis Nabi memiliki fungsinya yang paling utama sebagai penjelas (bayan). ${ }^{1}$ Sebagai sumber kedua ajaran Islam,

${ }^{1}$ Menurut Asy-Syatiby ada lima fungsi hadis terhadap al-Qur'an yaitu: 1) Hadis sebagai bayan Tafsibil, yaitu hadis memberikan rincian dan penafsiran terhadap ayat-ayat al-Qur'an yang masih bersifat global (mujmal) ; 2) Hadis sebagai bayan taqyid, adalah hadis memberikan batasan terhadap ayat-ayat al-Qur'an yang masih bersifat mutlaq; 3) bayan takhshish, yaitu hadis memberikan pengkhsususan terhadapat ayat-ayat al-Qur'an yang masih bersifat umum; 4) Bayan Ta'kid atau Bayan Taqrir, yaitu hadis menegaskan adn memperkuat hukum-hukum yang telah ditetapkan dalam 
menjadi mafhum bahwa hadis Nabi Muhammad Saw berfungsi sebagai penjelas (bayan) al-Qur'an, dalam konteks ini Nabi Muhammad saw diposisikan sebagai suri tauladan. ${ }^{2}$ Allah juga menegaskan dalam al-Qur'an bahwa misi kenabainnya sebagai rahmat bagi seluruha alam (rahmatan li al-'alamin). ${ }^{3}$ Dengan demikian, menjadikan segala tindak tanduk, tutur kata dan perilaku Nabi Muhammad saw untuk diteladani dan diikuti adalah kewajiban bagi umat Islam. Keteladan tersebut meliputi bagaimana kehidupan personal dan sosialnya, seperti sebagai suami dan sosok pemimpin dalam keluarga yang membangun rumah tangga yang sakinah ataupun dalam menciptakan kehidupan masyarakat bernegara dan berbangsa.

Walaupun Nabi diyakini ma'shum, namun sebagai manusia biasa, kehadiran Nabi saw. di dunia Arab tidak terlepas dari ruang dan waktu, sehingga dengan sendirinya hadis yang bersumber dari beliau dalam beberapa aspek terikat dengan dimensi ruang dan waktu. Dalam istilah Syuhudi Ismail hadis-hadis Nabi merupakan sumber ajaran Islam kedua yang memiliki substansi ajaran yang bersifat menyeluruh, terbatas serta lokalitas. ${ }^{4}$ Dalam Interpretasi dan pemahaman terhadap hadis ini, pada batas-batas tertentu dapat memunculkan berbagai pandangan yang berbeda. Perbedaan interpretasi dalam memahami hadis Nabi saw, dapat berimplikasi pada pengamalan praktek keagamaan dan ketetapan hukum yang yang ditimbulkan dan berlaku bagi umat Islam. Perbedaan imat ni juga pada gilirannya dapat melahirkan dan memunculkan sejumlah aliran keagamaan di kalangan umat Islam.

Munculnya pluralitas aliran keagamaan (Islam) di Indonesia tidak bisa dilepaskan dan atau sebagai dari akibat dari keragaman pemahaman dan interpretasi terhadap nash-nashs keagamaan (baca; al-Qur'an dan hadis) yang difahami dan dijadikan keyakinan sebagai regulasi utamanya. Eksistensi aliranaliran keagamaan tersebut memerankan posisinya dan bersinggungan langsung dengan masyarakat sebagai sasaran atau subyek dakwahnya. Tidak sedikit diantara aliran keagamaan yang muncul memperoleh penolakan dari sebagian kelompok masyarakat, terutama aliran keagamaan yang berhaluan keras atau radikal, namun ada juga aliran keagamaan yang diterima masyarakat, kendati di sana sini masih

al-Qur'an; dan 5) Bayan Tasyri', yaitu hadis menetapkan hukum-hukum baru yang tidak ada dalam al-Qur'an. Al-Syatibiy, al-Muwafaqat fi Ushul al-Abkam, Juz IV, (Beirut: Dar al-Fikr, t.t.), hal. 11.

2 "Sungguh telah ada pada diri Rasulullah suri taualadan yang baik bagi kalian.." (Q.S. AlAhzab/33: 21). Lihat Wahbah Zuhaili, dkk, al-Qur'an Seven in One, (Jakarta: al-Mahira, 2009) cet. II, hal. 421

${ }^{3}$ Q.S. Al-Anbiya/21: 107. Wahbah Zuhaili, dkk, al-Qur'an Seven in One..., hal. 332.

${ }^{4}$ Lihat Syuhudi Ismail, Hadis Nabi Yang Tekstual dan Kontekstual (Jakarta: Bulan Bintang, 1994), hal. 4. 
ada kritik dan penilaian negatif. Salah satu diantara aliran keagamaan dimaksud adalah Jamaah Tabligh. ${ }^{5}$

Terkait dengan eksistensi Jamaah Tabligh dengan aktivitas keagamaannya juga pernah diteliti oleh Wahyu Hidayat dengan judul "Taklim Keluarga bagi Pendidikan Akblak di Kalangan Jamaah Tabligh di Kota Bengkulu." Hasil penelitian dalam tesis tersebut adalah: Pertama, taklim keluarga yang dilakukan dibagi dua bagian, yakni 1) Membaca kitab (ta'lim kitabi). Adapun yang dikaji adalah kitab Fadhilah A'mal dan Sodaqah, serta Muntakhab Ahadis; 2) Mudzakarah sifat para sahabat Nabi Muhammad saw. Kedua, metode taklim kepada keluarga Jamaah Tabligh berupa metode nasehat berkaitan dengan ayat al-Qur'an dan hadis-hadis Nabi Muhammad saw. yang membangkitkan spirit serta motivasi dalam berbuat baik. Selain itu terdapat juga artikel ilmiah yang ditulis oleh Murkilim (2015) berjudul: "Pendekatan Dakwah Jamaah Tabligh di Kota Bengkulu."7 Bahwa pendekatan dakwah yang digunakan oleh Jamaah Tabligh adalah pendekatan khuruj. Dalam pendekatan ini dilakukan kegiatan-kegiatan sebagai berikut: tilawah, ta'lim wa ta'allum, tashbih al-Niyat, tarkiyah al-Nafs, dan kbidmat. Melalui kegiatan khuruj ini menghasilkan perubahan yang signifikan pada jamaahnya dalam bentuk peningkatan ilmu, amal dan kepribadian.

Persoalan ini menjadi menarik untuk diteliti dengan beberapa pertimbangan: Pertama, hadis merupakan sumber hukum utama kedua setelah alQur'an yang menempati posisi penting dalam menjelaskan (bayan) terhadap alQuran kaitannya dalam hukum Islam. Dengan demikian, hadis menjadi sangat urgen sebagai cetak biru dalam kehidupan umat Islam. Kedua, Sebagai sebuah agama, Islam memiliki pandangan dunia (worldcview) yang rahmatnya menyertai seluruh umatnya, include bagi Jamaah Tabligh selaku bagian dari fenomena komunitas umat Islam. Maka dari itu, menjadi nicaya dan tidak bisa dinafikan ketika rahmat itu akan melimpah kepada pemahaman keislaman yang menjadiakan hadis sebagai sumbernya.

Berdasarkan hasil penelusuran awal penulis, fenomena kelompok Jamaah Tabligh dalam mengamalkan hadis Nabi saw, ada kecenderungan tidak

${ }^{5}$ Penamaan Jamaah Tabligh, sesungguhnya bukan berasal dari kelompok jamaah sendiri. Karena dari berbagai literatur dan pandangan dari anggota kelompok jamaah ini, tidak ada "deklarasi" dan legalisasi untuk nama tersebut. Nama Jamaah Tabligh lebih popular di Malaysia. Sedangkan di Pakistan jamaah ini dikenal dengan sebutan al-Jamaah al-Tablighiyah atau al-Jamaah alIlyasiyyah. Sementara di Indonesia, selain nama Jamaah Tabligh, dikenal juga nama Jaulah. ${ }^{5}$ Nama Jamaah Tabligh tampak melekat kepada kelompok ini, karena kegiatan utama mereka adalah menyiarkan dan menyampaikan ajaran Islam (tabligh) kepada umat dan dakwah Islam amar ma'ruf nahi munkar. Aktivitas dakwah dan tabligh yang dilakukan kelompok ini, tidak saja berskala lokal dan nasional, tetapi sudah melewati batas-batas dan lintas antaranegara, transnasional.

${ }^{6}$ Lihat Wahyu Hidayat, Taklim Keluarga bagi Pendidikan Akblak di Kalangan Jamaah Tabligh di Kota Bengkulu.”Tesis, Program Pasca Sarjana IAIN Bengkulu, 2012.

${ }^{7}$ Dimuat dalam Jurnal Manhaj, Vol. 3 Nomor 1, Januari-April 2015. 
mempertimbangkan pada posisi dan kedudukan Nabi saw. tampak sosok Nabi saw. benar-benar harus diikuti, ditauladani dan dicontoh dalam berbagai aspek kehidupan. Kenyataan ini dapat dilihat dari pengamalan hadis yang secara konsisten dipraktekan oleh kelompok Jamaah Tabligh. Atas dasar asumsi ini, perlu dirumuskan paradigma dan konstruk pemahaman dan pengamalan hadis di kalangan Jamaah Tabligh.

Riset ini merupakan jenis riset lapangan (field research) yang berdasarkan pada data primer dan data sekunder. Kesemua data pada riset ini merupakan data kualitatif yang dipetakan kepada sumber data primer dan sumber data sekunder. ${ }^{8}$ Untuk data primer yang digunakan adalah setiap data yang berbentuk verbalisasi ucapan, tindakan atau perbuatan sebagai perilaku yang didapatkan dari informan penelitian. Sementara data sekundernya ialah semua data yang didapatkan berupa produk dokumentasi baik gambar foto dan video serta segala bahan-bahan informatif baik berupa buku, artikel, jurnal, prosiding dan webbsite yang dapat menjadi tambahan data primer serta kualified sebagai referensi serta punya korelasi dengan tujuan penelitian ini. Maka, peneliti menggunakan metode deskriptif kualitatif.

Untuk mendapatkan data-data yang dibutuhkan pada melakukan penelitian ini, cara yang digunakan meliputi pengamatan awal atau observasi, penggalian informasi dengan wawancara dan menggunakan dokumentasi. Setiap data yang telah diperoleh perlu dilakukan uji keabsahannya dengan menggunakan teknik triangulasi. Adapun implentasinya dalam penelitian ini adalah dengan melakukan triangulasi dengan sumber dan metode, yang memiliki arti melakukan komprasi dan kroscek di balik validitas informasi dan data yang dihasilkan melalui waktu dan alat yang berbeda dalam metode kualitatif.

Teknik analisa yang digunakan pada penelitian ini merujuk pada teori Kartini yaitu interactive model yang mengklasifikasikan analisa data kepada tiga tahapan yaitu: Pertama, Reduksi data (Data Reduction). Yang dimaksud reduksi data pada penelitian ini iaalah suatu proses pemilahan, pemusatan perhatian pada penyederhanaan, pengabstrakan dan transformasi data kasar yang muncul dari catatan-catatan tertulis di lapangan. Kedua Penyajian data (Data Display) Data yang ditemukan dari hasil pengamatan awal dan penggalian lanjutan dengan wawancara akan disusun secara sistematis, sehingga memungkinkan adanya penarikan kesimpulan. Ketiga, Melakukan verifikasi utuk membuat kesimpulan (Verification).

Oleh karena itu, penelitian ini bertujuan untuk: mengetahui pemahaman kelompok Jamaah Tabligh terhadap sunnah Nabi; untuk mendeskripsikan pengamalan hadis-hadis Nabi di kalangan Jamaah Tabligh. Pemahaman dan

${ }^{8}$ Kartini Kartono, Pengantar Metodologi Riset Sosial (Bandung: Mandar Maju, 1996), hal. 20. 
pengalaman jamaah tabligh terhadap hadis Nabi. Dalam penelitian ini difokuskan pada hadis-hadis tentang makan berjamaah, menggunakan siwak, memanjangkan jenggot, mencukur kumis, memakai surban dan gamis serta larangan isbal.

\section{Perkembangan Jamaah Tabligh di Bengkulu.}

Tahun 1993 Jamaah mulai masuk ke Kota Curup ditolak oleh pihak pemerintah, Jamaah dikembalikan ke daerah masing-masing. Sejak tahun 1994 mulai diterima oleh Pemerintahan, yang datang ketika itu Jamaah dari Jakarta, Bogor dan Pemalang. Rombongan Jamaah ini ketika datang ke Bengkulu ini dalam rangka khuruj fi sabilillah selama 4 (empat) bulan, yang dipimpin oleh Yusuf dari Bogor. Jamaah ini masuk ke Masjid Jami, dan Kebon Ros.

Setelah mendapat penerimaan dan respon yang baik dari pemerintah, Jamaah mulai melakukan pertemuan-pertemuan setiap satu minggu satu kali. Beberapa anggota Jamaah yang melakukan pertemuan, yang sekaligus sebagaii Jamaah awal, diantaranya: Najib (Suprapto), Bastari (Sawah Lebar), Abdul Gofar (Tanah Patah), Rusmin (Gunung Bungkuk), Abdul Hadi (Lubuk Durian), Cik Ardiansyah (Muhajirin), dan Darwin (Sumur Meleleh). Pusat kegiatan (Markaz) pada masa ini bertempat di Masjid Jami' Suprapto.

Seiring dengan perkembangan Jamaah, pada tahun 1995 markaz dipindahkan ke Masjid al-Iman di Tanah Patah sampai tahun 1996. Beberapa Jamaah yang aktif pada masa ini sudah mulai bertambah, dengan jumlah Jamaah sekitar 20 orang se kota Bengkulu. Selain jamaah yang yang sudah aktif pada periode awal perkembangan, beberapa jamaah yang aktif mulai tahun 1995 antara lain: Maruf (Pagar Dewa), Faisol (Pagar Dewa), Muslihun (Hibrida), Sulaiman (Pagar Dewa), Munzilin (Tanah Patah), Royyan, Sihabudin, Iskandar dan Gusti Santoso. ${ }^{10}$

Jumlah Jamaah pada tahun 1996 mulai bertambah lagi, yang aktif pada tahun ini sekitar 50 orang jamaah. Sejak tahun 1996 sampai tahun 2006, markaz bertempat di Masjid Muhajirin Lingkar Barat. Selama sekitar 10 tahun bermarkaz di Masjid Muhajirin, sudah banyak Jamaah yang datang dari luar negeri yang melakukan khuruj baik selama 40 hari maupun 4 bulan, dengan jumlah Jamaah bervariasi antara 15 sampai dengan 20 orang Jamaah. Beberapa Negara yang pernah berkunjung ke Bengkulu antara lain: India, Pakistan, Malaysia, Thailand, Arab Saudi, Yordania dan Yaman.

Sejak tahun 2006 markaz Jamaah bertempat di Masjid al-Salam (Pagar Dewa) dengan jumlah Jamaah sudah mencapai 2000-an lebih. Sampai tahun 2017, sudah banyak Jamaah yang datang dari luar negeri yang melakukan khuruj ke

\footnotetext{
${ }_{9}^{9}$ Wawancara dengan Ust. Muhamad Faishol, Sa btu 05 Juni 2017

${ }^{10}$ Wawancara dengan Ust. Faishol, Ahad, 06 Juni 2017.
} 
Bengkulu, antara lain: Pakistan (4 kali), India (12 kali), Banglades (10 kali), Arab Saudi (5 kali), Yaman (2 kali), Yordania (2 kali), Quwait (2 kali), Mesir (2 kali), Malaysia (6 kali), Thailand (3 kali) dan Singapura (1 kali). ${ }^{11}$

\section{Pemahaman dan Pengamalan Hadis-hadis di kalangan Jamaah Tabligh}

Bahwa Jamaah Tabligh dalam mendefinisikan terma sunnah lebih mengarah kepada definisi yang dinarasikan oleh ulama Hadis. Pengertian hadis yang dimaksud adalah semua hal yang disandarkan kepada Nabi Muhammad saw baik ketika beliau telah diangkat menjadi Rasul atau sesudahnya (Qabla al-Bi'stah ay Ba'dahu), meliputi setiap perkataan dan perbuatan, sifat dan hal ikhwal. Oleh karenanya, pemahaman Jamaah tabligh menjadi niscaya untuk mengikuti segala sesuatu yang bersumber dari Nabi Muhammad Saw. Semua itu dinyatakan sebagai sunnah, walaupun praktek yang dilakukan Nabi Muhammad saw pada kapasitas sebagai manusia biasa. Dengan begitu, semua yang dilakukan nabi outomatically adalah sunnah dan semaksimal mungkin untuk dilakukan dalam kehidupan seharihari. Berikut beberapa pemahaman hadis dan pengamalannnya di kalangan jamaah tabligh:

\section{Hadis tentang makan berjamaah}

Berdasarkan referensi dan hasil wawancara dari informan Jamaah Tabligh, bukanlah perkara ibadah shalat saja yang harus dikerjakan secara berjamaah, akan tetapi makanpun disunahkan untuk dilakukan secara berjamaah. Adapun hadis yang sejalan dengan makan berjamaah adalah berikut:

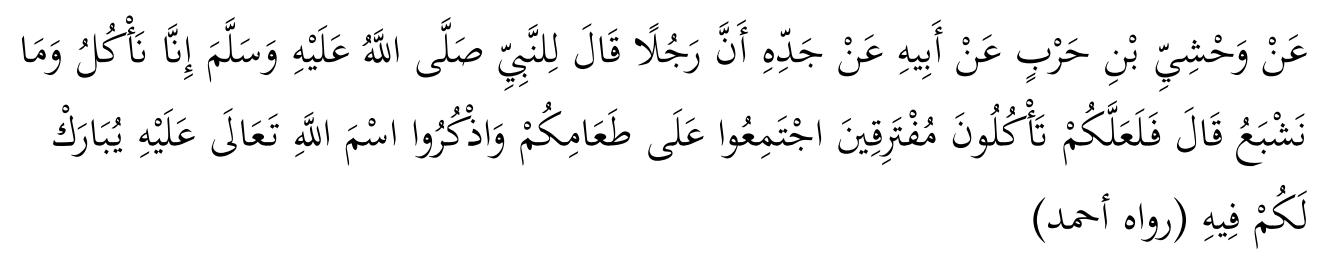

"...ada seorang laki-laki berkata kepada Nabi saw, kami makan, tapi tidak merasakan kenyang. (Rasulullah Saw) bersabda: "Mungkin kalian makan dengan berpencar-pencar, maka berkumpullah ketika makan, dan sebutlah nama Allah Ta'ala, semoga kalian akan diberi berkah di dalamnya" (HR. Abmad). ${ }^{12}$

${ }^{11}$ Wawancara dengan Ust. Syahrin, Sabtu, 26 Juni 2017.

12 HR. Ahmad, no. 15498, Kitab. Musnad Penduduk Makkah, Bab. Hadis Wahsyi alHabsyi dari Nabi. Lihat Ensiklopedi 9 Imam Hadis, www.lidwapusaka.com 
Dalam matan yang berbeda, Rasulullah Saw juga bersabda pada hadis Muslim dari sahabat Jabir:

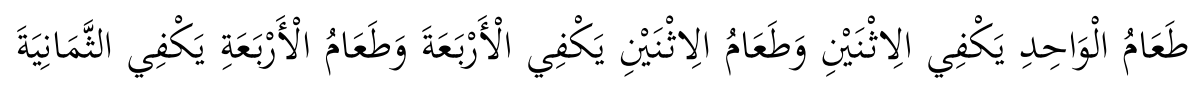

Dari Jabir radbiallabu anbu, aku mendengar Rasulullab saw bersabda: "Makanan satu orang cukup untuk dua orang, makanan dua orang cukup untuk empat orang, dan makanan empat orang cukup untuke delapan orang." (HR. Muslim) ${ }^{13}$

Secara normatif, sebagian jamaah mengetahui dengan baik dan sebagian lain tidak mengetahui dalil yang digunakan tersebut. Namun secara umum dan lazim digunakan jamaah tabligh adalah kitab-kitab yang menjadi referensi karya Maulana Muhammad Yusuf al-Kandahlawi yaitu Muntakhab Ahadis, karya Maulana Muhammad Zakariya al-Kandahlawi yaitu Fadilah A'mal. Menurut H. Mukhtar, salah seorang Jamaah yang berdomisili di Pagar Dewa, dia mengatakan:

"Saya tidak mengetahui tentang dalil yang menganjurkan untuk makan berjamaab; saya mempraktekan makan berjamaah, karena melihat umumnya Jamaah makan secara berjamaah dalam satu nampan, terutama pada saat ada pertemuan-pertemuan (musyawarah) di markas atau pada saat khuruj ke masjid-masjid. Babkan pada awalnya saya tidak suka makan berjamaah dalam satu nampan, tetapi setelah saya khuruj selama tiga hari, saya mulai terbiasa makan berjamaah. Makan berjamaah dalam satu nampan, bersama tiga atau empat jamaah, bisa lebih praktis. "14

Ustadz Makruf, salah seorang jamaah yang tinggal di Komplek Pesantren al-Salam menyatakan bahwa dia mengetahui seputar dalil disunnahkannya makan berjamaah. Ketika penulis melakukan wawancara, dia memberikan jawaban dengan mengutip hadis: "Makanan yang dimakan oleh 1 orang (dimakan sendirian); bisa cukup untuk 2 orang (dimakan secara berjamaah); makanan untuk 10 orang yang dimakan sendiri-sendiri (tidak berjamaah); bisa cukup untuk 20 orang, jika dimakan secara berjamaah. Demikian juga makanan untuk 100 orang yang dimakan sendiri-sendiri, bisa cukup untuk 200 orang, yang dimakan secara berjamaah. ${ }^{15}$

\section{Hadis tentang menggunakan siwak.} adalah:

Adapun hadis yang berkaitan dengan penggunaan siwak di antaranya

${ }^{13}$ Hadis ini diriwayatkan dalam jalur sanad Ishaq bin Ibrahim dari Rauh 'Ubadah; dari, Yahya bin Habib; dari Rauh; dari Ibnu Juraij; dari Abu Az Zubair; dari Jabir. Lihat HR. Muslim, No. 3836, Kitab. Minuman, Bab. Makan dua orang cukup untuk tiga orang. Lihat Ensiklopedi Hadis Kitab 9 Imam. www.lidwapusaka.com

${ }^{14}$ Wawancara dengan H. Mukhtar, Jum'at, 7 Juni 2017

15 Wawancara dengan Ust. Ma'ruf, Minggu, 9 Juni 2017 


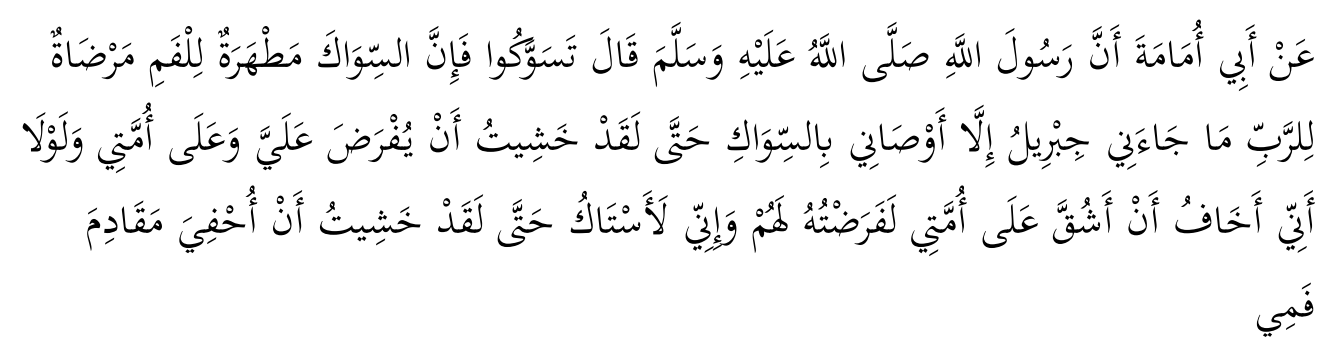

Dari Abu Umamah bahwa Rasulullah saw bersabda: "Hendaklab kalian bersiwak, sesunggubnya siwak dapat membersibkan mulut dan menjadikan Rabb ridla. Tidaklah Jibril datang kepadaku kecuali menasihatiku untuke bersiwak. bingga aku takut jika hal itu diwajibkan atasku dan umatku. Sekiranya aku tidak khawatir memberatkan umatku sunggub akan aku wajibkan mereka untuk bersiwak. Dan aku selalu bersiwak bingga aku khawatir gigi depanku terkikis."16

Meski demikian, penulis melihat bahwa secara umum, Jamaah yang diwawancarai tidak semuanya hapal dengan baik hadis atau dalil disunnahkannya menggunakan siwak, mereka hanya mengetahui tentang anjuran tersebut berdasarkan bacaan dari bebarapa buku atau kitab dan mendengar pada saat bayan dilakukan pada saat pertemuan atau kburuj fi sabilillah.

Seperti yang diutarakan Fakhruraziy, salah seorang Jamaah yang berdomisili di Pagar Dewa, dia mengatakan: bahwa dirinya tidak mengetahui tentang dalil yang menganjurkan untuk memakai siwak; dia memakai siwak, karena melihat umumnya Jamaah memakainya. Hal yang senada disampaikan oleh H. Mukhtar, bahwa dia tidak mengetahui dalil tentang disunnahkannya memakai siwak. ${ }^{17}$

\section{Hadis tentang memanjangkan janggut dan memotong kumis.}

Amalan lain yang dipraktekan oleh kalangan Jamaah Tabligh adalah mencukur kumis dan memanjangkan janggut atau jenggot. Berdasarkan penelusuran penulis, untuk hadis yang berkorelasi pada perintah mencukur kumis dan memanjangkan janggut yaitu:

16 Maulana Muhammad Zakariyya al-Kandahlawi, Kentamaan Memelihara Janggut dan Bersiwak, Penyunting Musthafa Sayani, dkk, (Bandung: Pustaka Ramadhan, 2007), hal. 61. Jalur sanad ini adalah Hisyam bin Ammar dari Muhammad bin Syu'aib dari Utsman bin Abu 'Atikah dari Ali bin Yazid dari Al Qasim dari Abu Umamah. Lihat HR. Ibnu Majah, no. 25, Bab Siwak dalam Ensiklopedia Hadis Kitab 9 Imam, www.lidwapusaka.com

${ }^{17}$ Wawancara dengan Fakhrurazi dan H. Mukhtar, Ahad, 6 Juni 2017 


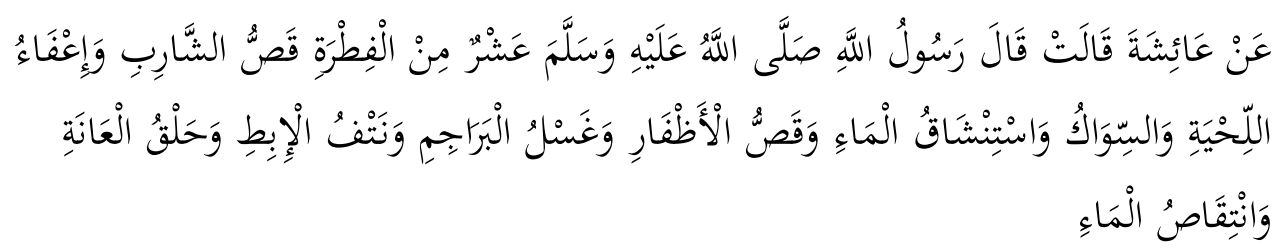

Dari Aisyah dia berkata, Rasulullah saw bersabda, "Sepuluh perkara yang termasuk fitrah, yaitu; mencukur kumis, memanjangkan jenggot, bersiwak, beristinsyaq (memasuk.kan air ke bidung), memotong kuku, bersuci dengan air, mencabut bulu ketiak, mencukur bulu kemaluan dan beristinja dengan air." (HR. Muslim). ${ }^{18}$

Dalam hadis lain disebutkan, dari Ibnu Umar r.a, berkata bahwa Rasulullah saw. Bersabda:

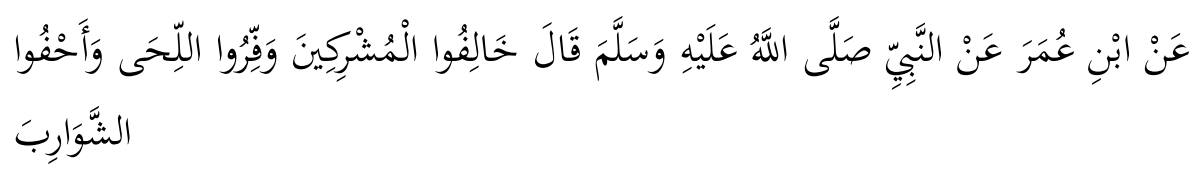

Dari Ibnu Umar dari Nabi shallallabu alaibi wasallam beliau bersabda, "Selisibilah orangorang musyrik, panjangkanlah jenggot dan cukurlah kumis kalian.". (HR. Bukhari)"

Dalam wawancara kepada subyek penelitian tentang pendapatnya memanjangkan jenggot dan mencukur kumis, Ustadz Saepudin menjelaskan bahwa Islam adalah indah, menyukai yang indah-indah. Memanjangkan jenggot bagian dari keindahan. Selain itu, memanjangkan jenggot menjadi pembeda dan penciri kaum muslimin dengan kaum Yahudi dan Nasrani. Kaum Yahudi biasanya memanjangkan jenggot dan kumis sekaligus, sedangkan Nasrani mencukur jenggot dan memanjangkan kumis. ${ }^{20}$ Ungkapan senada dikemukakan oleh Ustadz Ma'ruf, dan dia menambahkan, pembeda dengan kaum Majusi, mereka mencukur jenggot dan kumisnya, keduanya dibersihkan. Dengan memanjangkan jenggot, pahalanya bisa mengalir terus selama jenggot itu tidak dipotong. Sedangkan pahala amal/ibadah yang lain (seperti salat) bisa berhenti pahalanya, ketika seseorang tidak melaksanakan shalat. ${ }^{21}$ Selain itu, menurut pengetahuan Yagi Saputra dari beberapa buku yang dibaca, disebutkan bahwa

${ }^{18}$ Sanad hadis ini adalah Qutaibah bin Sa'id dan Abu Bakar bin Abu Syaibah serta Zuhair bin Harb dari Waki' dari Zakariya bin Abu Zaidah dari Mush'ab bin syaibah dari Thalq bin habib dari Abdullah bin az-zubair dari Aisyah Lihat HR. Muslim, no. 384, Kitab. Thaharah, Bab. Macam Fitra; HR. Abu Daud, no. 49, Kitab Thaharah, Bab. Bersiwak termasuk dari fitrah. Lihat. Ensiklopedia Hadis 9 Kitab Imam, www.lidwapusaka.com

19 Jalur sanadnya adalah Muhammad bin Minhal dari Yazid bin Zurai' Umar bin Muhammad bin Zaid dari Nafi' dari Ibnu Umar. Lihat HR. Bukhari Nomor. 5442. Kitab Pakaian, Bab. Memotong Kuku; HR. Muslim, no. 382, Kitab. Thaharah, Bab. Macam Fitrah. Lihat, Ensiklopedia Hadis, 9 Kitab Imam, www.lidwapusaka.com

${ }^{20}$ Wawancara dengan Ust. Saepudin, Sabtu, 15 Juni 2017

${ }^{21}$ Wawancara dengan Ust. Ma’ruf, Minggu, 6 Juni 2017 
setiap helai dari jenggot mengandung pahala kebaikan. Masih menurut Yagi, berjenggot bagian dari ittiba (mengikuti) sunnah Rasul, dan pada sunnah, pasti ada kejayaan. ${ }^{22}$ Sedangkan menurut $\mathrm{H}$. Mukhtar, dengan memanjangkan jenggot seseorang akan diperhitungkan orang lain dan bisa meminimalisir untuk berbuat dosa. ${ }^{23}$

Senada dengan Zul Herman yang menyatakan bahwa memanjangkan jaggut adalah sunnah Nabi, meski demikian, Zul Herman tidak terlalu hafal dan memusingkan terkait hadisnya apa atau persoalan fiqihnya. Akan tetapi lebih menekankan kepada ittiba kepada sunnah Nabi. Dalam hal ini dia mengatakan:

"Bagi saya babwa memanjangkan jenggot adalah bagian dari ittiba sunnah Nabi. Saya juga tidak terlalu melihat pada aspek. fiqibnya, dan tidak. juga hafal hadisnya secara kbusus. Saya lebih kepada berusaba mengamalkan apa yang telah saya dengar dan saya lihat dari para jamaah yang umumnya juga telah memanjangkan jenggot setelah mengikuti pengajian dan aktif dalam jamaah '24

\section{Hadis tentang memakai surban.}

Dari hasil wawancara peneliti, jamaah tabligh memiliki pemahaman sendiri terkait membiasakan penggunaan sorban. Dalam pemahaman mereka bahwa penggunaan surban selain merupakan perbuatan sunnah rasulullah saw, juga terdapat berbagai kebaikan dan fadilahnya. Beberapa hadis yang menjadi landasan dalam penggunaan surban di antaranya:

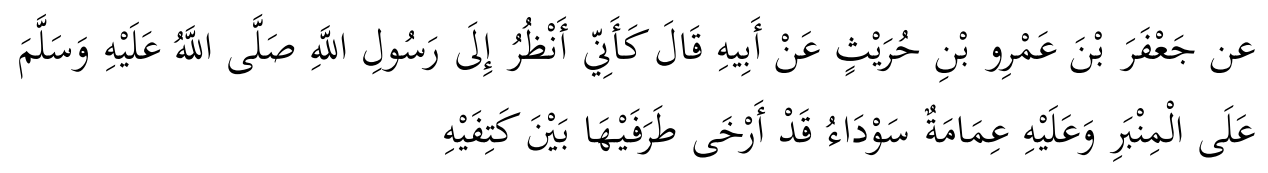

Dari Ja'far bin Amru bin Huraits dari bapaknya ia berkata, "Sepertinya aku melihat Rasulullah shallallahu alaibi wasallam di atas mimbar dengan mengenakan surban bitam yang kedua ujungnya telab beliau turunkan di antara kedua pundak.."25

22 Wawancara dengan Yagi Saputra, Sabtu, 12 Agustus 2017

${ }^{23}$ Wawancara dengan H. Mukhtar, Minggu, 13 Agustus 2017

24 Wawancara dengan Zul Herman, 30 Juli 2017

${ }^{25}$ Sanad hadis ini adalah Abu Bakr bin Abu Syaibah dan Al Hasan Al Hulwani dari Abu Usamah dari Musawir Al Warraq dari Ja'far bin Amru bin Huraits. Lihat HR. Muslim, no. 2421, Kitab. Haji, bab. Bolehnya masuk Makkan tanpa ihram, HR. Abu Daud, no. 3555, Kitab. Pakaian, Bab. Imamah. Lihat Ensiklopedi Hadis 9 Kitab Imam, www.lidwapusaka.com 
Dalam riwayat al-Nasai dari Zabir disebutkan juga bahwa pada fath Makkah, Nabi Muhammad masuk ke Makkah dengan mengenakan surban berwarna hitam dan bukan dalam keadaan ihram. ${ }^{26}$

Terkait seputar pengetahuan tentang anjuran memakai soraban, salah seorang Jamaah yang berdomisili di Pagar Dewa, dia mengatakan: bahwa dirinya tidak mengetahui tentang dalil yang menganjurkan untuk memakai sorban; dia mempraktekannya karena melihat banyak jamaah yang memakai sorban. Dia tidak mengetahui juga hikmah dibalik pakaian sorban, bagi dirinya karena hal tersebut perintah Rasul, maka dia laksanakan ${ }^{27}$ Senada dengan pandangan tersebut, informan lainnya, Fakhrurozi tidak mengetahui dalil tentang disunnahkannya memakai sorban. Dia mempraktekkan karena melihat jamaah lain melaksanakannya, dan sudah menjadi kebiasaan jamaah, banyak memakai sorban. ${ }^{28}$

Dalam pandangan jamah tabligh lainnya yang diwawancarai, bahwa fadilah mengenakan surban tidak akan diperoleh pada saat mengenakan pecih putih (Kopiah), hal ini disebabkan perbedaan keduanya. Ketika mengenakan surban dengan panjang kisaran 10 hasta, maka dililitkan di kepala hingga menjuntai ke belakang seperti ekor., sementara bentuk peci yang, saat mengenakannya dapat dimasukan ke kepala secara langsung. ${ }^{29}$

Sebagian besar Jamaah Tabligh mengkategorikan praktek ini sebagai sunnah yang diamalkan secara terus menerus dan berkesinambungan karena slalu dilakukan oleh Nabi Muhammad saw (istimrariah) Menurut mereka, perintah Nabi untuk mengenakan surban kepada kita selaku umatnya bertujuan untuk syiar selaku seorang muslim dan dapat menjadi pembeda dalam berpakaian dengan pemeluk agama lainnnya.

\section{Hadis tentang memakai gamis.}

Jika melihat cara berpakaian kalangan Jamaah Tabligh, maka satu kata akan terucap umumnya mereka menggunakan gamis dalam aktivitas kesehariannya, baik dalam konteks ibadah maupun muamalah sosial. Gamis merupakan pakaian kurung yang panjang selutut atau hingga di atas mata kaki. Gamis juga dikenal dengan jubah yang familir dikenakan orang Arab dan Timur Tengah. Meski begitu, masyarakat muslim Indonesia lainnya exclude jamaah tabligh, sebagian juga mulai dan banyak yang mengenakan gamis ketika

${ }^{26}$ HR. Al-Nasai, no. 5249, Kitab. Perhiasan, Bab. Memakai Surban Hitam. Lihat Ensiklopedi Hadis 9 Kitab Imam, www.lidwapusaka.com

27 Wawancara dengan H. Mukhtar, Ahad, 27 Agustus 2017.

28 Wawancara dengan Fakhrurazi, Ahad, 13 Agustus 2017.

${ }^{29}$ Wawancara dengan Ust. Wahyu Hidayat, Sabtu, 19 Agustus 2017. 
melaksanakan shalat di rumah maupun di masjid. Berikut hadis yang berkaitan dengan gamis yang menjadi landasan jamaah tablihg dalam pemakaiannya:

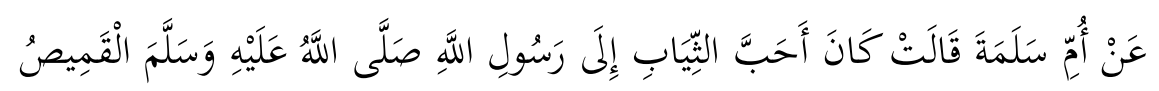

Dari Ummu Salamah ia berkata, "Pakaian yang paling disukai oleh Rasulullah shallallahu alaibi wasallam adalah gamis." 30

Berdasarkan hadis di atas, kalangan Jamaah Tabligh berkesimpulan bahwa menjadi sunnah yang baik untuk dilakukan yaitu memakai gamis karena merupakan pakaian yang dikenakan nabi Muhammad saw beserta para sahabatnya. Betapa Rasululllah saw begitu mencintai pakaian ini, terlebih gamis merupakan pakaian yang menjadi penutup tubuh secara menyeluruh. Menurut Maulana Zakaria al-Kandahlawi, bahwa gamis merupakan pakaian terbaik yang menutup semua bagian badan yang wajib ditutup dan memenuhi ketampanan serta keagungan bagi yang memakainya. ${ }^{31}$

Subyek informan, Mukhtar memberikan komentar:

Dengan memakai gamis, dianggap ulama dan sering dibormati. Babkan saya sering disandingkan dengan orang-orang besar, seperti Menteri Agama, kapolda dll. Merasa terhormat, ketemu polisi juga tidak susah. Saya tidak tabu dalilnya, saya tidak pernah mikir keutamaan-kentamaannya. Saya tidak banyak tanya, yang penting saya langsung kerjakan. ${ }^{32}$

Menurut Ustadz Wahyu, ketika memakan gamis, kita sedang berpakaian sebagai usaha untuk mengikuti sunnah Nabi Muhammad saw; menjaga dari kemaksiatan dan dosa. Karena dengan menggunakan gamis dapat menghalangi seseorang melakukan kemungkran. Berdasarkan pengalaman jamaah, ketika di Afrika dan Thailand (10\% Islam) selalu ada yang meingatkan apabila akan masuk ke restoran-restoran non halal. Ketika pakai gamis akan diberitahukan dan diarahkan ke restoran yang halal. ${ }^{33}$

\section{Hadis tentang larangan isbal.}

Salah satu fenomena dalam cara berpakaian Jamaah Tabligh adalah tidak isbal. Isbal adalah menjulurkan kain, sarung, celana yang melewati batas mata kaki,

${ }^{30}$ Sanad hadis ini adalah Ali bin Hujr dari Al Fadhl bin Musa dari Abdul Mukmin bin Khalid dari Abdullah bin Buraidah dari Ummu Salamah. Lihat HR. Tirmizi, no. 1686, Kitab. Baju, Bab. Gamis; HR. Abu Daud, no. 3507, Kitab. Pakaian dan Perhiasan, Bab. Penjelasan tentang Gamis (kemeja). Lihat Ensiklopedi Hadis 9 Kitab Imam, www.lidwapusaka.com

${ }^{31}$ Maulana Fazlurrahman Azami, Hukum dan Fadbilah Janggut..., hal. 147.

32 Wawancara dengan H. Mukhtar, Ahad, 27 Agustus 2017.

33 Wawancara dengan Ust. Wahyu Hidayat, Sabtu, 5 Agustus 2017. 
Menurut mereka, menggunakan gamis sebagaimana dijelaskan di atas, perlu kehati-hatian agar gamis yang dikenakan tidak melebihi mata kaki sebab itu sesuatu yang dilarang nabi Muhammad saw. Jamaah tabligh punya pemahaman larangan isbal karena ada ancaman dalam hadis bagi yang isbal dalam berpakaian ancaman api neraka. Rasulullah saw bersabda:

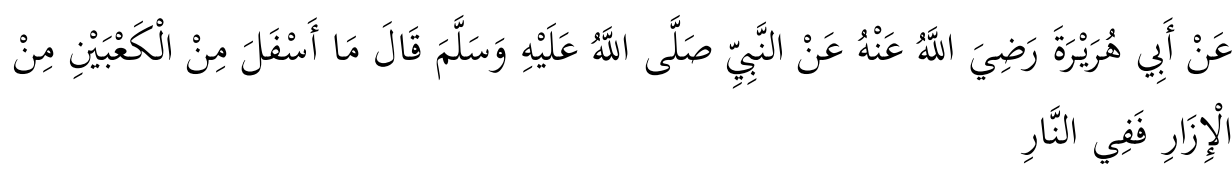

Dari Abu Hurairah rra dari Nabi Saw beliau bersabda, "Barangsiapa menjulurkan kain sarungnya bingga di bawah mata kaki, maka tempatnya adalah neraka." ${ }^{134}$

Dari hadis yang disebutkan di atas, secara tekstual memang terdapat keterangan berupa ancaman neraka bagi siapa yang memakai kain melebihi bawah mata kaki. Pemahaman tekstual apa adanya dalam hadis Nabi Muhammad saw inilah yang tampak di kalangan jamaah tabligh. Menurut mereka, hadis ini menginformasikan perbuatan terlarang dari Nabi Muhammad saw yang berakibat neraka yaitu pemakaian sarung, gamis, atau celana yang panjangnya melewati mata kaki. Maka inilah yang menjadi dasar jamaah tabligh dalam berpakaian yang tidak isbal.

Menurut Ustad Saepudin tidak Isbal merupakan bentuk kehati-hatian; bukan semata karena sombong. Bagi jamaah bukan semata tidak karena sombong; yang lebih penting adalah ittibanya kepada nabi Muhammad saw. Bukan semata kalau isbal, nanti masuk neraka. Paling tidak, memekai gamis menjadikan kita dapat pahala sunnahnya. Terhindar dari kemungkinan adanya najis yang terinjak, ketika kain itu menjulur. ${ }^{35}$ Hal yang senada dikemukakan juga oleh informan lainnya, seperti H. Mukhtar, Yagi Saputra dan Ust. Wahyu Saputra, Antoni dan Zul Herman.

\section{Analisis Pemahaman dan Pengamalan Hadis Jamaah Tabligh}

Berdasarkan data-data di atas, dapat dijelaskan bagaimana pemahaman hadis jamaah tabligh dan implikasinya dalam praktek keagamaannya. Terkait makan secara berjamaah dalam satu nampan, ini merupakan praktek yang dilakukan ketika mereka dalam satu kegiatan seperti pada saat khuruj, ítikaf d dan

\footnotetext{
${ }^{34}$ Sanad hadis ini adalah dari Adam dari Syu'bah dari Sa'id bin Abu Sa'id Al Maqburi dari Abu Hurairah. Lihat HR. Bukhari, no. 5341, Kitab. Pakaian, Bab. Apa yang di bawah kaki adalah bagian dari neraka; HR. al-Nasai, no. 5235, Kitab. Perhiasan, Bab. Kain sarung di bawah mata kaki; HR. Ahmad, no. 7155, Kitab. Musnad sahabat yang banyak meriwayatkan hadis, Bab. Musnad Abu Hurairah. Lihat Ensiklopedi Hadis 9 Kitab Imam, www.lidwapusaka.com

35 Wawancara dengan Ustad Saepuddin., Sabtu, 15 Juni 2017
} 
taklim. Mereka terbiasa makan berdua, bertiga, hingga berenam dalam satu nampan. Kalangan Jamaah Tabligh selalu mempedomani etika makan yang mereka yakini sebagai sunnah Rasul, diantaranya: duduk di lantai, duduk di atas kaki kiri lutut kanan diangkat, membaca basmalah dan doa sebelum makan. Pada saat makan, tangan kanan yang digunakan dengan tiga jari, saat makan dimulai dari tepi bukan di tengah, dari posisi terdekat makanan diambil, dilarang berlebihan ketika makan, ada keharusan makanan dihabiskan yang ada di nampan, selesai makan jari tanganpun dijilat, bersyukur atas makanan, dan membaca doa setelah makan. ${ }^{36}$

Diantara sunnah tasyriłyyah ketika makan adalah makan secara bersamasama, makan dengan tangan kanan, diawali dengan melafazkan bismillah, makan dimulai dari tepi bukan di tengah, makan diambil dari posisi terdekat, dilarang berlebihan ketika makan, selesai makan jari tanganpun dijilat, bersyukur atas makanan, dan membaca doa setelah makan. Jika diperhatikan dasar yang bersumber dari hadisnya, secara tegas umat Islam diperintahkan atau minimal dianjurkan untuk mengikuti anjuran tersebut. Menggunakan tangan kanan saat makan, melafazkan bismillah dan mengambil makanan yang terdekat merupakan sunnah yang sangat dianjurkan.

Sunnah makan berjamaah sangat dianjurkan karena keberkahan akan turun dalam jamaah. Dikatakan mengandung keberkahan karena secara lahiriyah bisa lebih hemat dan tidak boros; sedangkan secara bathiniah terciptanya kebersamaan, kedekatan dan kasih sayang sesama hingga persatuan. Sedangkan makan dengan tiga jari lalu menjilati jari-jari bahkan menjilati piring supaya tidak menyisakan makanan, bukan sebuah keniscayaan, meskipun disebut sebagai sunnah nabi Muhamamd saw. Secara subtantif, ada pesan kepada kita yang mengajarkan kesyukuran atas karuniaNya, sehingga ketika makan kiranya tiada menyisakan makanan terbuang secara sia-sia.

Praktek berikutnya adalah penggunaan siwak di kalangan jamaah tabligh. Dalam menggunakan siwak sebagai salah satu sunnah, tidak semua jamaah mengamalkan memakai siwak ini secara istiqamah. Dengan kata lain, ada yang istiqamah memakai siwak dan ada yang tidak. Menurut salah seorang informan, salah satu alasan tidak/belum istiqamah dalam bersiwak ini, karena sudah terpengaruh oleh pemikiran rasional,tampaknya memakai siwak sudah bisa diganti dengan pasta gigi. ${ }^{37}$

Terkait dengan kayu yang digunakan untuk bersiwak, informan dari Jamaah Tabligh menyebutkan bahwa siwak yang digunakan harus merupakan

${ }^{36}$ Hasil Wawancara dan observasi di Pesantren As-Salam Bengkulu.

${ }^{37}$ Wawancara dengan Ustad. Saepudin, Ahad, 27 Agustus 2017. 
kayu arak atau zaitun seperti yang digunakan nabi Muhammad saw dan para sahabatnya. Apabila kayu siwak yang digunakan berbeda, apalagi menggunakan sikat gigi dan pasta gigi, keutamaan sunnah tidak akan didapatkan. ${ }^{38}$ Bagi penulis, pehamaman tekstualis seperti ini berangkat dari pembacaan secara harfiah dari matan hadis dengan tidak mengambil makna di balik teks hadis tersebut. Sementara itu, dari berbagai referensi buku yang ditulis oleh tokoh Jamaah Tabligh, ditemukan keterangan tentang kebolehan bersiwak dengan alat lain di luar kayu siwak. ${ }^{39}$ Walaupun ada kebolehan serta kelonggaran boleh menggunakan alat selain kayu siwak, umumnya mereka masih dengan argumentasi bahwa lebih utama bersiwak dengan kayu siwak, karena itu merupakan praktek amaliah Nabi Muhammad saw. Selain itu, fakta ditemukan secara ilmiah bahwa kayu siwak (arak) memiliki kandungan zat yang baik untuk kesehatan gusi dan gigi. ${ }^{40}$

Pada prinsipnya, pandangan di atas adalah bentuk pemahaman sunnah berdasarkan spirit dan pesan yang terkandung dalam hadis. Begitupun Hadis tentang bersiwak yang terkandung di dalamnya spirit untuk senantiasa menjaga kebersihan gigi dan mulut. Untuk alat yang digunakan dapat menyesuaikan situasi dan kondisi yang berlaku pada masanya. Saat bersiwak disunnahkan pada waktuwaktu yang baik seperti ketika akan mendirikan shalat wajib lima waktu ataupun shalat nawafil (shalat sunnah).

Terkait dengan sunnah memelihara janggut, selain berdasarkan hadis nabi Muhammad saw, jamaah tabligh juga merujuk pada buku Hukum dan Fadbillah Jenggot karya Maulana Fazlurrahman Azhami. Dalam buku itu ditegaskan bahwa adalah wajib hukumnya untuk memanjangkan janggut dan haram hukumnya bagi siapa yang mencukurnya menjadi pendek apalagi ketika tidak sampai segenggam. Bahkan keharaman mencukur janggut menurut mereka sejalan dengan pendapat jumhur ulama dan imam mazhab yang empat. ${ }^{41}$

Dalam pemahaman hadis memelihara janggut dan implikasinya terhadap prakteknya, kita dapat melihat mayoritas mereka memang tidak mencukurnya bahkan memanjangkannya. Karena ini merupakan bagian dari pengamalan sunnah nabi Muhammad saw yang disebut sunnah buda. Bahwa setiap amaliah Nabi Muhammad saw dalam upaya menyempurnakan ibadah dan diikuti oleh para sahabat inilah yang disebut sunnah buda. Dengan begitu, apapun yang menjadi praktek amaliah tersebut lebih dekat kepada perkara wajib utuk dilaksanakan dan menjadi semacam penyimpangan jika ditinggalkan. Di antara amaliah itu adalah

38 Wawancara dengan Yagi Saputra, Sabtu, 26 Agustus 2017.

${ }^{39}$ Maulana Athar Husen, Kentamaan dan Manfaat Siwak, terj. Alimuddin, (Bandung: Pustaka Ramadhan, 2008), hal. 224.

${ }^{40}$ Maulana Athar Husen, Fadbilab dan Fedah Siwak..., hal. 178.

41 Maulana Fazlurrahman Azhami, Hukum dan Fadbillah Jenggot, (Bandung: Pustaka Ramadhan, 2008), hal. 74 . 
pelaksanaan shalat berjamaah, kumandang azan dan sikap teguh pendirian atau istiqamah. ${ }^{42}$

Dalam penelusuran penulis, secara umum jamaah tabligh menggunakan hadis-hadis qauli yang dijadikan hujjahnya. Terkait dengan memanjangkan janggut, matan hadis tersebut mengandung perintah nabi yang wajib dilakukan untuk membiarkan janggut menjadi panjang dan mencukur kumis. Hal ini juga diutarakan salah satu jamaah tabligh yang menyampaikan bahwa setiap apa yang dituntukan nabi termasuk perintah, maka dibalik itu pasti ada hikmahnya. Dalam pemahaman mereka, bahwa hadis ini bertujuan untuk memberikan distingsi antara umat Islam dengan selainnya. Terlebih agar tampak distingsi jelas antara laki-laki dan wanita. Pengamalan ini juga diperkuat dengan pemahaman adanya larangan mencukur janggut dan haram hukumnya berdasarkan pendapat para fuqaha. ${ }^{43}$

Menurut Qardhawi, problem janggut memang bukan termasuk perkara wajib ataupun perkara rukun dalam beragama, akan tetapi tidak bisa dinafikan bahwa ada tujuan dan hikmah dibalik itu semua. Penciptaan laki-laki dan wanita yang berbeda secara fisik dan fitrahnya, sehingga memanjangkan janggut menjadi pembeda yang jelas antara keduanya. Ditambahkan oleh Qardhawi bahwa janggut yang panjang tanpa mencukurya hingga terlihat beda dengan umat lain adalah persoalan sekunder dan penyempurna (mukammilat) kepribadian seorang muslim. Ini bukanlah perkara primer atau sesuatu yang urgen dalam beragama. Dalam simpulannya, Qardhawi menyatakan bahwa sunnah hukumnya memanjangkan janggut dan makruh jika mencukurnya. Meski begitu, memanjangkan janggut bukan juga sebuah kewajiban dan berdosa jika mencukurnya (baca: haram). ${ }^{44}$

Terkait dengan sunnah memakai surban, memang terdapat keragaman hadis-hadis yang dijadikan hujjah. Berdasarkan status hadisnya, hadis yang digunakan adalah shabih yang dikategorikan pada hadis perbuatan (fi'liy) yang memotret pribadi nabi Muhamamd saw saat mengenakan surban, baik waktu berwudhu, melaksanakan shalat, mendapatkan wahyu, pada saat fath al-Makkah dan berkhutbah. Begitu juga pada moment nabi Muhammad saw dalam keadaan sakit hingga menjelang tutup usia, bahwa nabi Muhammad tetap dalam posisi

\footnotetext{
42 Maulana Fazlurrahman Azhami, Hukum dan Fadbillah Jenggot..., hal. 110.

${ }^{43}$ Maulana Muhammad Zakariyya al-Kandahlawi, Keutamaan Memelihara Janggut dan Bersiwak.., hal. 22.

${ }^{44}$ Yusuf Qardhawi, Al-Quran dan Sunnah Referensi Tertinggi Umat Islam, terj. Bahruddin Fanani, (Jakarta: Rabbani Pers, 1997), hal. 263.
} 
memakai surban. ${ }^{45}$ Sedangkan salah satu hadis yang menjadi hujjah dan informatif tentang keistimewaan menggunakan surban masuk kategori hadis lemah (dhaif) dan palsu (maudhu). Maulana Fazhlurrohman pun mengakui status hadis tersebut adalah lemah. ${ }^{46}$ Meskipun demikian, masih ada di antara Jamaah Tabligh yang berhujjah dengan hadis palsu ini yang berbunyi sebagai berikut:

$$
\text { صالاة بعمامة تعدل خمسا و عشرين صلاة بلا عمامة وجمعة بعمامة تعدل سبعين بلا عمامة }
$$

"Orang yang salat memakai sorban sebanding dengan duapulub lima kebaikan orang yang salat tanpa memakai surban."

Selain itu hadis tentang penggunaan gamis sebenarnya tidak termasuk sunnah tasyriiyah akan tetapi merupakan sunnah ghairu tasyri'iyyah dikarenakan berkesesuaian dengan tradisi dan situasi yang berlaku saat itu. Begitu juga dengan menggunakan gamis (qamis), yang merupakan sunnah nabi Muhammad saw hal dalam sifatnya adalah hadis perbuatan (fi'liy). Dari hadis ini kita diinformasikan bahwa Nabi Muhammad saw menyukai bakan termasuk yang sangat disukai untuk dikenakan yaitu gamis. Dengan begitu, bisa difahami jika jamaah tabligh banyak yang menggunakan gamis karena termasuk dalam mengikuti kebiasaan nabi yang berarti mengamalkan sunnah nabi Muhammad saw.

Qardhawi menegaskan bahwa perkara penggunan pakaian, style dan modenya lebih berhubungan dengan kondisi lingkungan dan situasi masyarakt tertentu yang satu sama lain tidak mesti sama. Ada tradisi, adat, perbedaan strata sosial dan ekonomi, iklim dan cuaca, kecenderungah hati serta faktor-faktor lainnya. Sehubungan dengan ini, Islam memberikan ruang yang dinamis dan fleksibel dengan syarat tetap sesuai syariat. Bahwa berpakaian harus menutup aurat, longgar dan besar, tidak ketat dan membentuk lekuk tubuh, tidak tipis nan transparan, atau dalam menggunakan pakaian dengan gaya sombong dan pamer, maka semua itu dikategorikan terlarang karena bertentangan dengan nilai-nilai syariat.

Dalam hal ini Qardhawi juga mengutip pendapat Ibnu Hajar al-Asqalani saat menelaah dan mengkaji hadis di atas. Menurutnya hadis larangan menjulurkan sarung adalah ketika diikuti dengan rasa sombong dan sikap sombong termasuk dosa besar ${ }^{47}$, bahkan Allah memang tidak suka kepada orang yang

${ }^{45}$ Maulana Muhammad Zakariyya al-Kandahlawi dan Fazlurrahman Azami, Hukum dan Fadbilah Janggut, Rambut, Peci, Sorban, Gamis dan Siwak Menurut al-Quran dan Hadis, terj. Alimuddin Tuwu, (Bandung: Pustaka Ramadhan, 2008), hal. 114-115.

${ }^{46}$ Muhammad Zakariyya al-Kandahlawi dan Fazlurrahman Azami, Hukum dan Fadbilah Janggut ..., hal. 140-141.

${ }^{47}$ Yusuf Qardhawi, Kaifa Nata'amal ma'a al-Sunnah al-Nabawiyyah, (Dar al-Wafa, 1992), hal. 106. 
menyombongkan diri. ${ }^{48}$ Sebaliknya, kita bisa memahami bahwa jika menggunakan sarung melebihi mata kaki atau menyeretnya, tapi tidak diikuti dengan rasa sombong, maka tidak berlaku haram. Hal ini sejalan dengan keterangan dari informan yang menyebutkan bahwa tidak isbal bukan semata karena sombong atau tidak sombong, melainkan lebih kepada kehati-hatian, terhindar kemungkinan terkena najis dan terinjak. ${ }^{49}$

Begitu juga kita harus melihat lebih dalam makna substansi hadis tersebut. Substansi hadis adalah menyuruh kaum muslimin berpakaian sederhana tidak berlebihan, tidak mewah, berbangga-bangga atau sombong. Oleh sebab itu perlunya pemahaman substantif dalam hadis larangan isbal yaitu dalam berpakaian jangan sampai berlebih-lebihan, apalagi diikuti dengan rasa sombong karena pakaian yang digunakan mahal harganya.

Dari beberapa hadis di atas yang dipahami dan diamalkan oleh Jamaah Tabligh, jika dilihat dari paradigma pemahaman hadis Syuhudi Ismail, ${ }^{50}$ dapat dideskripsikan bahwa kandungan petunjuk hadis dalam pandangan Jamaah Tablig, hanya dikorelasikan dengan fungsi dan peran Nabi Muhammad saw sebagai Rasulullah, sehingga semua sunnah Rasul yang harus diikuti dan ditaati. Pemahaman dan pengamalan hadis di kalangan mereka tidak menghubungkannya dengan berbagai peran Nabi Muhammad saw lainnya seperti Nabi sebagai kepala pemimpin masyarakat, panglima perang, hakim dan pribadi. Atas dasar pemahaman ini, Jamaah Tabligh memiliki kecenderungan memahami dan mengamalkan hadis secara tekstual. Hadis dipahami apa adanya, sebagaimana yang tersurat dalam teks tersebut. Mereka tidak memahami dan mengamalkan hadis-hadis Nabi secara kontekstual, memahami hadis berdasarkan makna yang tersirat dibalik redaksi teks suatu hadis. Paradigma pemahaman hadis secara tekstual dan hanya mempertimbangkan peran nabi sebagai Rasulullah akan berimplikasi pada kandungan ajaran Islam yang bersumber dari hadis bersifat universal, tidak mengenal batas waktu (temporal) dan batas kewilayahan (lokalitas).

\footnotetext{
48 Allah telah menegaskan larangan berlaku sombong dalam al-Quran diantaraya: QS. Lukman/31: 18, QS. Al-Nisa/4: 36.

${ }^{49}$ Hasil wawancara dengan Ustad Saepudin, Sabtu, 19 Agustus 2017.

${ }^{50}$ M. Syuhudi Ismail, Hadis Nabi yang Tekstual dan Kontekstual: Telaah Ma'anil Hadis tentang Ajaran Islam yang Universal, Temporal dan Lokal, (Jakarta: Bulan Bintang, 1994). Dalam menjelaskan beberapa hadis (hal. 34-46), Syuhudi Ismail selalu menghubungkan kandungan hadis dengan peran dan fungsi Nabi, misalnya Nabi sebagai Rasulullah, Nabi sebagai kepala pemimpin masyarakat, panglima perang, hakim dan pribadi. Selain itu, dia melengkapi juga dengan pendekatan pemahaman hadis, baik secara tekstual maupun kontekstual.
} 


\section{Kesimpulan}

Tulisan ini dapat diambil simpulan yaitu, bahwa Jamaah Tabligh dalam mendefinisikan terma sunnah lebih mengarah kepada definisi yang dinarasikan oleh ulama Hadis. Oleh karenanya, ada pemahaman Jamaah tabligh menjadi niscaya untuk mengikuti segala sesuatu yang bersumber dari Nabi Muhammad Saw. Semua itu dinyatakan sebagai sunnah, walaupun praktek yang dilakukan Nabi Muhammad saw pada kapasitas sebagai manusia biasa.

Dengan pemahaman seperti ini, menjadi maklum ketika jamaah tabligh menampilkan amalan dan performa harian dengan menyebut apa yang dilakukan mengikuti nabi Muhammad saw dan para sahabat, hal ini menjadi landasan untuk mengamalkan apa yang menjadi sunnah nabi Muhammad saw dalam berpakaian seperti memanjangkan janggut, makan secara bersama-sama atau berjamaah, mengenakan gamis, memakai peci dan surban serta menggunakan siwak.

Bahwa sunnah difahami dalam tiga bentuk yang berimplikasi pada praktek kegamaan jamaah tabligh. Pertama, sunnah yang memuat segala cerita dan peristiwa yang dialami nabi Muhammad saw sejak terbangun dari tidur hingga kembali tidur (Sirah). Kedua, sunnah yang menampilkan performa dan style nabi Muhammad saw dalam keseharian (Shurah). Ketiga, sunnah yang berkaitan dengan perkara batin yang dirasakan nabi Muhammad saw (sarirah) seperti kegundahan hati terhadap nasib umatnya, perasaan hati beliau dan sebagainya.

Secara umum, jamaan tabligh menjadikan karya Maulana Muhammad Zakaria Yusuf al-Kandahlawi dan Maaulana Muhammad Yusuf al-Kandahlawi sebagai rujukan dan referensi dalam beramal. Terlebih memang kitab Muntakhab Ahadis dan Fadhail A'mal menjadi konsumsi utama dalam setiap taklim dan kegiatan pengajia (baca; bayan) jamaah. Akan tetapi tidak semua jamaah mengetahui bahkan hafal hadis-hadis yang dijadikan bujjah dalam beramal.

\section{Bibliografi}

Al-Jauziyah, Ibn Qayyim, I'lam al-Muwaqqi'in, Juz. III, (Beirut: Dar al-Fikr al'Ilmiyyah, 1991).

Al-Qardhawi, Yusuf, as-Sunnah Mashdaran li al-Ma'rifah wa al-Hadharah, (Kairo: Dal al-Syuruq, 1998).

W. Munawwir, Kamus Al-Munawwir Arab-Indonesia Terlengkap (Jakarta: Pustaka Progresif, 1997).

Abu Bakar dan Hikmatur Rahmah, Fatwa Ulama Seputar Jama'ah Tabligh (Jakarta: Pustaka Al-Haura', 2002).

al-Qazwini, Abu 'Abdillah Muhammad bin Yazid [Ibn Majah] (Riyad: Dar alMa'arif, t.th.). 
Arifuddin Ahmad, Metodologi Pemahaman Hadis: Kajian Ilmu Ma'ani al-Hadis (Makassar: Alauddin University Press, 2012).

al-Suyuthi, Jalal al-Din , Jami' al-Shagir, (Beirut: Dar al-Fikr, t.th.).

Al-Syatibiy, al-Munvafaqat fi Ushul al-Ahkam, Juz IV, (Beirut: Dar al-Fikr, t.t.)

An-Nadhar M. Ishaq Shahab, Khuruj fi Sabilillah, (Bandung: Pustaka Ramadhan, 2007).

al-Suyuthi, Jalal al-Din, Jami' al-Shagir, (Beirut: Dar al-Fikr, t.th.).

al-Farmawi, Abd. Al-Hayy, al-Bidayah fi al-Tafsir al-Maudhu': Dirasah Manhajizah Maudhu'iyyah, terj. Suran A. Jamrah, Metode Tafsir Maudhui: Suatu Pengantar (Cet. I; Jakarta: Raja Grafindo Persada, 1994).

Ash-Shiddieqy, Hasbi, Sejarah dan Pengantar Ilmu Hadis (Jakarta: Bulan Bintang, 1988).

al-Shalih, Subhi, Ulum Hadis wa Musthalabub (Beirut: Dar al-Malayin, 1988).

Ajjaj al-Khatib, Muhammad, Ushul al-Hadis Ulumuhu wa Mushthalabuh (Beirut: Dar al-Fikr, 1975).

Dawud, Abu, Sunan Abi Dawud, juz II, (Beirut: Dar al-Fikr, 1988).

Ensiklopedi Hadis 9 Kitab Imam, www.lidwapusaka.com

Hidayat, Wahyu, "Taklim Keluarga bagi Pendidikan Akhlak Anak di Kalangan Jamaah Tabligh di Kota Bengkulu”, (Tesis, IAIN Bengkulu, 2012).

Ismail, Syuhudi , Hadis Nabi Yang Tekstual dan Kontekstual (Jakarta: Bulan Bintang, 1994).

Ilyas, Abustani dan La Ode Ismail Ahmad, Filsafat Ilmu Hadis.

Kholil, Syukur dkk, Peta Dakwah Sumatera Utara (Medan: Perdana Publishing, 2010).

Khallaf, Abdul Wahhab 'Im Ushul al-Fiqh, (Kuwait: Dar al-Qalam) 
558 | AL QUDS : Jurnal Studi Alquran dan Hadis vol. 5, no 2, 2021

Halaman ini sengaja dikosongkan 